\title{
Risk reduction and perceived collective efficacy and community support among female sex workers in Tamil Nadu and Maharashtra, India: the importance of context
}

\author{
Mohua Guha, ${ }^{1}$ Angela Baschieri, ${ }^{2}$ Shalini Bharat, ${ }^{1}$ Tarun Bhatnagar, ${ }^{3}$ \\ Suvarna Sanjay Sane, ${ }^{4}$ Sheela V Godbole, ${ }^{4}$ Saravanamurthy P S, \\ Mandar Keshav Mainkar, ${ }^{4}$ Joseph Williams, ${ }^{5}$ Martine Collumbien ${ }^{2}$
}

${ }^{1}$ Centre for Health \& Social Sciences, School of Health Systems Studies, Tata Institute of Social Sciences, Mumbai, India

${ }^{2}$ Department for Population Studies, London School of Hygiene and Tropical Medicine, London, UK

${ }^{3}$ National Institute of Epidemiology (ICMR), Chennai, India

${ }^{4}$ National AIDS Research Institute (ICMR), Pune, India ${ }^{5}$ Chartered Voluntary Health Services, Chennai, India

\section{Correspondence to} Martine Collumbien, Department for Population Studies, London School of Hygiene and Tropical Medicine, Keppel Street, London WC1E 7HT, UK; martine.collumbien@ Ishtm.ac.uk

Accepted 9 May 2012 Published Online First 3 July 2012

\section{UNLCKI:D}

This paper is freely available online under the BMJ Journals unlocked scheme, see http:// jech.bmi.com/site/about/ unlocked.xhtml

\begin{abstract}
Background Empowering sex workers to mobilise and influence the structural context that obstructs risk reduction efforts is now seen an essential component of successful HIV prevention programmes. However, success depends on local programme environments and history.

Methods The authors analysed data from the Integrated Behavioural and Biological Assessment Round I crosssectional survey among female sex workers in Tamil Nadu and Maharashtra. The authors used propensity score matching to estimate the impact of participation in intervention activities on reduction of risk (consistent condom use) and vulnerability (perceived collective efficacy and community support).
\end{abstract}

Results Background levels of risk and vulnerability as well as intervention impact varied widely across the different settings. The effect size ATT of attending meetings/ trainings on consistent condom use was as high as $21 \%$ in Tamil Nadu (outside of Chennai) where overall use was lowest at $51 \%$. Overall, levels of perceived collective efficacy were low at the time of the survey; perceived community support was high in Tamil Nadu and especially in Chennai (93\%) contrasting with 33\% in Mumbai. Consistent with previous research, the context of Mumbai seems least conducive to vulnerability reduction, yet selfhelp groups had a significant impact on consistent condom use $(A T T=10 \%)$ and were significantly associated with higher collective efficacy (ATT=31\%). Conclusions Significant risk reduction can be achieved by large-scale female sex worker interventions, but the impact depends on the history of programming, the complexity of the context in which sex work happens and pre-existing levels of support sex workers perceive from their peers.

\section{INTRODUCTION}

Building strong local community groups has become central to HIV prevention programming among hard-to-reach and marginalised communities. ${ }^{1}$ In India, the much cited Sonagachi Project has been held up as a model for peer-led interventions and community mobilisation among female sex workers (FSWs) in achieving high condom use. ${ }^{2-6}$ Central to the success was the fact that sex workers were not treated as beneficiaries of prevention programmes. Instead, intervention strategies emphasised sex workers' representation, active participation and empowerment to act collectively in order to reduce vulnerability. ${ }^{2}$ This led the government of India and funders interested in the scale-up of sex workers interventions to view community mobilisation as essential to effectiveness and sustainability of HIV prevention. $^{8}$

Avahan, the India AIDS Initiative of the Bill \& Melinda Gates Foundation, started implementing HIV prevention among FSWs in 2004, mainly in Southern India. Individual behaviour change among FSW is promoted through peer-led outreach enhancing knowledge, teaching condom negotiation skills and encouraging regular sexually transmitted infection (STI) screening. As a supportive social environment is important in shaping the success of peer-led approaches, ${ }^{4}{ }^{910}$ sex workers need to be organised so they can collectively challenge power relationships and structural barriers that contribute to their vulnerability. ${ }^{11}$ Community mobilisation works through the pathways of social capital and social spaces for dialogue and empowerment of marginalised communities while facilitating reaching out to larger numbers of FSWs. ${ }^{10}{ }^{12}$ Avahan's strategies include bringing sex workers together through trainings and meetings and supporting the formation of self-help groups, bringing about changes at the community level. By creating safer spaces for communities to exchange information, selfhelp groups foster solidarity among sex workers. ${ }^{13}$ In the knowledge that peers will also insist on condom use, sex workers feel more motivated to negotiate with clients ${ }^{714}$ and more empowered to reduce their risk behaviour. ${ }^{1} 791516$ Organising sex workers facilitates the formation of community-based organisations, fostering leadership and building the capacity of FSWs to run interventions themselves. These community-based organisations are then able to negotiate with powerful others on behalf of other sex workers, leading to changes at the community level like reducing violence from police and discrimination in health settings ${ }^{10}{ }^{16}$ that typically undermine FSWs' health. Collectivisation is thus not just an instrumental means to risk reduction but a dynamic process to be valued as an outcome in itself. $^{12}$ The local prevailing political and social context will determine the ease with which communities can be mobilised. ${ }^{1} 91315$

In this paper, we consider consistent condom use as an indicator of risk reduction and sex worker's 
positive perception of community collectivisation and support as measures of vulnerability reduction. We use a 2006 crosssectional bio-behavioural survey done 18 months after scale-up of Avahan interventions started. We assess how levels of risk and vulnerability vary across different contexts in Maharashtra and Tamil Nadu. To address the limitations of non-randomisation in the cross-sectional survey design, we evaluate the effect of interventions using propensity score matching (PSM), comparing outcomes among FWSs participating in intervention activities with matched controls who have not participated.

\section{METHODOLOGY \\ Sample}

The data used in these analyses are from the Integrated Behavioural and Biological Assessment Round I (IBBA-I) for districts in Maharashtra and Tamil Nadu (between March and July 2006). This cross-sectional survey among FSWs used probability sampling with two-stage cluster sampling. Conventional cluster sampling was used for FSW in brothels and time location cluster sampling for street-based FSWs.

A sample size of 400 per district was adopted, but where the sampling frame suggested fewer than 400 sex workers in a district, a 'take all' approach was used. Eligibility criteria included a minimum age of 18 and having exchanged money for sex at least once in the month before the interview. The data instrument covered topics on demographics, sexual history, condom use with different types of partners, self-reported STI symptoms, health seeking behaviour, exposure to interventions and questions on community-led structural interventions. Respondents gave informed consent before the interview and ethics approval was obtained from the Ethics and Scientific boards of the implementing institutes. For further details of the IBBA methodology, see Saidel et a $1^{17}$

We run the analysis separately for the metropolitan areas (Chennai and Mumbai) from the rest of the state of Tamil Nadu (districts of Coimbatore, Dharmapuri, Madurai, Salem) and Maharashtra (Pune, Yavatmal, Kolhapur). Mumbai combines the brothel-based and street-based samples in Mumbai and Thane. We refer to Mumbai and Thane as 'Mumbai' and to the other districts in Maharashtra as 'rest of Maharashtra'. Equally, 'the rest of Tamil Nadu' refers to the districts excluding Chennai.

\section{Variables}

\section{Outcome variables}

Biological outcomes, such as HIV or STI infections, could not be used in this analysis. HIV being a lifetime infection could not be linked to intervention exposure in the last year. The prevalence of acute STIs was too low to be used as an outcome. Hence, we considered three outcome variables, reflecting impact of the interventions at an individual level (consistent condom use with clients) and community level (perceived collective efficacy and perceived community support).

\section{Consistent condom use with all clients}

Individual protection against HIV/STIs was measured by consistent condom use, based on answers to several questions in different contexts throughout the questionnaire. The respondent was considered to use condoms consistently when she reported (1) always using condoms with both regular and occasional clients (or either if she only had one type of client), (2) having used condom at last sexual intercourse with regular and (/or) occasional client, (3) no occasion in the last week when a client did not use a condom, (4) no time in the past month that she wanted to use a condom with a client but has not used it and (5) used condom at last anal sex with client (if any).

\section{Collective efficacy}

This outcome was derived from the hypothetical question: 'If there were a problem that affected all or most of the sex work community, how many sex workers would work together to deal with the problem?' Those who answered either 'most' or 'all' were recoded as having high collective efficacy and those who said 'no one' or 'some' as low collective efficacy. ${ }^{15}$

\section{Community support}

Community support was elicited by the question: 'Can you tell me, when you are sick or tired, how do other sex workers/ members of your community take care of you?' When the respondent replied she received food, medicines, nursing care or any other support, she was considered as perceiving community support. No support was assigned when she replied that others do not care at all.

\section{Exposure variables}

We did not differentiate between Avahan and non-Avahan interventions but considered the impact of all available HIV interventions. All respondents who were aware of the services delivered by Avahan or non-Avahan funded NGOs were asked a series of questions on the kind of exposure. We use two measures of 'active exposure' or 'participation': (1) took part in a meeting or training organised by the NGO and (2) became a member of a self-help group supported by the NGO (this is in contrast to 'passive' exposure of being contacted by a peer educator). In a different section of the questionnaire, the respondent was asked a separate question about her membership of a sex worker collective. This is considered here as evidence of grass roots activity separate from the Avahan programmes.

\section{Covariates}

Background characteristics or covariates considered in the PSM analysis included age(/age groups), age at first sex, age at first sex work experience, cohabitation, district, educational group (illiterate, primary, secondary+), frequency of alcohol consumption (everyday, once/week, less than once a week, never), whether or not had a vaginal discharge in the previous 12 months, whether had occasional clients, whether had regular clients, the number of other regular (non-paying) partners in previous month, place of sexual encounter (bar, home, lodge, public place) and place of solicitation (bar, home, lodge, public place, phone).

\section{Analysis}

We conducted bivariate analyses using $\chi^{2}$ test to assess the relationship between consistent condom use and the exposure variables (attending trainings or meetings, being a member of a self-help group and being a member of a sex worker collective). We did the same with the collective outcomes (collective efficacy and community support) and also look at their association with consistent condom use.

In order to measure the impact of the exposures, we compared the outcomes in FSWs exposed to the intervention to those who were equally as likely to be exposed but were not. For those exposures that were found to have a significant association $(p<0.05)$ with the outcomes, we applied the PSM technique to control for the background characteristics that affect the propensity to be exposed to the intervention as well as the outcomes of interest. To achieve this, the PSM technique uses a logistic regression model conditional on a set of background 
characteristics to calculate the propensity of each respondent to be exposed to the intervention. ${ }^{18}$ These propensity scores are probabilities and thus range between 0 and 1 . Individuals with similar propensity scores are considered to be comparable in respect to all the measured background characteristics.

Individuals with similar propensity score were matched using the radius matching method ${ }^{19}$ specifying a calliper of 0.03 . This method reduces the risk of using poor matches as it uses all the possible comparison group members within the maximum distance of the caliper. We estimated the Average Treatment effect on those Treated (ATT) which is the difference in the outcome of interest among the treated (those exposed to the intervention) and matched untreated (not exposed to the intervention) groups. ${ }^{18}$ In order to assess whether the ATT is statistically significant, we estimated bootstrapped SE around the estimates. ${ }^{20} 21$

We checked the assumptions underlying the PSM procedure. First, covariates included in the model for creating the propensity score have to create balanced propensity among the entire distribution of scores. ${ }^{22-24}$ This was checked via the $<$ pscore $>$ command in STATA. Second, the covariates used in the overall model should balance the difference between the treated and the untreated groups, that is, the difference in characteristics between the matched treated and untreated groups is not statistically significant. ${ }^{1822} 25$ This further check was done by applying the command < ptest $>$ in STATA. We used STATA V.11 for all analyses.

\section{RESULTS}

The levels of exposure to interventions vary widely in the different sites (table 1). Receptive exposure in terms of being contacted by a peer educator ranges from $30 \%$ in Chennai to $71 \%$ in the rest of Tamil Nadu. In Tamil Nadu, nearly all those contacted by a peer educator went on to participate in a meeting or training. The level of more 'active' participation in joining self-help groups is generally much lower. Membership in sex workers' collective is overall very low in both states with none reported in Chennai and a high of $12 \%$ in the rest of Tamil Nadu.

Levels of condom use were highest in the rest of Maharashtra (84\%) but much lower in Mumbai (69\%), whereas in Tamil Nadu, they were much higher in Chennai (83\%) than in the other districts (51\%). The belief that most sex workers would stick together to tackle a problem that affects all FSW was not very prevalent. This dimension of community power (perceived collective efficacy) does not vary much between metropolitan and the other district in Tamil Nadu (26\% vs $28 \%$ ). However, in Maharashtra, it is much lower in Mumbai than in other districts
(20\% vs $46 \%$ ). Perceived community support ranged from a low $33 \%$ in Mumbai to $93 \%$ among FSW in Chennai.

\section{Bivariate analysis of effect of intervention exposure on outcomes}

Table 2 presents the different levels of perceived collective efficacy by exposure to or participation in the intervention activities. Having attended a meeting or training was significantly associated with both collective efficacy and community support, in all areas except Mumbai, where this effect was not significant for community support. Collective efficacy was significantly associated with belonging to a self-help group in the rest of Tamil Nadu and Mumbai. In both states outside of the metropolises, members of self-help groups were significantly more likely to perceive community support.

In Chennai, no sex worker collectives were reported, but in the rest of Tamil Nadu and in Mumbai, members perceived higher collective efficacy and community support.

Perceived collective efficacy and community support were in turn significantly associated with higher consistent condom use in rest of Tamil Nadu and rest of Maharashtra. In Chennai, the FSWs with perceived community support had significantly higher condom use.

Table 3 presents differentials in consistent condom use with all clients by participation in training and by membership in SHG and SWC. In Chennai, where condom use is high, there is no effect of training and being a member of a self-help group. In the rest of Tamil Nadu, condom use is significantly higher in those attending trainings and self-help groups. In Mumbai, members of self-help groups or of sex worker collectives had significantly higher condom use.

Measuring the impact of the intervention strategies using PSM Where the bivariate analysis showed a statistically significant effect of exposure on outcomes, we use PSM to assess programme impact. One of the initial steps of the PSM methodology is to estimate a logistic model of the probability to be exposed to a community initiative and the first test checks that this model achieves balance. For the probability of attending training organised by an NGO, we failed to get a balanced model in Mumbai; for the probability to being a member of a self-help group, we failed to get a balanced model in the rest of Tamil Nadu. For these two associations, we could not measure the effect using the PSM methodology since the difference between FSW exposed and FSW not exposed could not be fully explained by the observed covariates.

The effect of intervention exposure on levels of collective efficacy and community support are presented in table 4.

Table 1 Exposure to intervention strategies, consistent condom use, collective efficacy and community support among female sex workers in Tamil Nadu and Maharashtra, Integrated Behavioural and Biological Assessment Round I

\begin{tabular}{|c|c|c|c|c|c|c|}
\hline$\%$ & $\begin{array}{l}\text { Tamil Nadu State } \\
(\mathrm{N}=\mathbf{2 0 3 2})\end{array}$ & $\begin{array}{l}\text { Chennai } \\
(\mathrm{N}=410)\end{array}$ & $\begin{array}{l}\text { Rest of } \\
\text { Tamil Nadu } \\
(\mathrm{N}=1622)\end{array}$ & $\begin{array}{l}\text { Maharashtra } \\
\text { State }(N=2525)\end{array}$ & $\begin{array}{l}\text { Mumbai } \\
(\mathrm{N}=1596)\end{array}$ & $\begin{array}{l}\text { Rest of } \\
\text { Maharashtra } \\
(\mathrm{N}=926)\end{array}$ \\
\hline \multicolumn{7}{|l|}{ Per cent exposure to/or participation in interventions } \\
\hline Took part in meeting or training organised by an NGO & 57.5 & 29.7 & 64.6 & 28.5 & 22.9 & 38.1 \\
\hline Member of a self-help group supported by the NGO & 26.1 & 8.5 & 30.5 & 9.0 & 10.5 & 6.5 \\
\hline Member of a sex worker collective & 9.5 & 0 & 12.0 & 3.4 & 4.2 & 1.9 \\
\hline Collective efficacy & 27.5 & 25.9 & 27.8 & 29.7 & 20.2 & 46.0 \\
\hline Community support & 80.0 & 93.3 & 77.2 & 44.4 & 32.5 & 64.8 \\
\hline
\end{tabular}




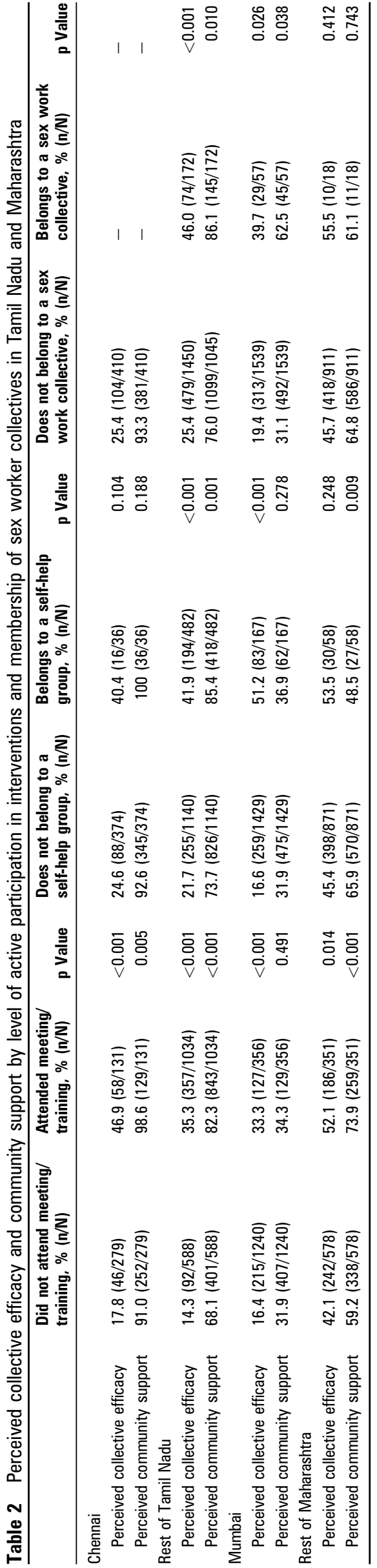

The level of collective efficacy and community support among the exposed (treated) in the column 1 can be compared with the level among the matched sample of non-exposed individuals (control) in column 2. The average treatment effect among the treated ATT in column 3 is the difference in collective efficacy and community support (column 1-2). Columns 4 and 5 show the bootstrap SE and its significance level. Overall model balance was achieved for all significant effect presented, confirming that there was no significant difference in covariates between treated and matched controls, and hence that the ATT estimate obtained from the model is reliable.

In Maharashtra, we found that $53 \%$ of FSW who attended training had reported collective efficacy compared with $42 \%$ of the matched controls. In Chennai, the average effect on the treated was $30 \%$. The effect of participating in training/meeting on community support was significant in the rest of Maharashtra and in both groups in Tamil Nadu. Being a member of a self-help group had a large effect on collective efficacy in Mumbai $(A T T=31 \%)$. In both Mumbai and in the rest of Tamil Nadu, membership of a sex worker collective had a big and statistically significant impact on both collective efficacy and on community support.

For collective efficacy and consistent condom use, the average effect on the treated was 16\% in rest of Tamil Nadu and 5\% in rest of Maharashtra. Both were statistically significant $(p<0.05)$. Perceived community support also had a statistically significant impact on consistent condom use in rest of Tamil Nadu (ATT $=7.5 \%, \mathrm{p}=0.03$ ) and rest of Maharashtra (ATT $=7.2 \%, \mathrm{p}=0.02$ ). Using the observed covariates, we could not find a balanced model for the effect of community support on consistent condom use in Chennai.

Table 5 shows the results of the PSM analyses for consistent condom use. Among FSW who attended a meeting or training organised by the NGOs in the rest of Tamil Nadu, 59\% consistently used a condom with all clients, whereas among the 'matched' FSW who did not attend, only 38\% used condoms consistently. The Average Treatment effect on the Treated (ATT) was thus $21 \%$ difference. The bootstrapped SE $(2 \%)$ show that this difference was statistical significant $(p<0.001)$. In the rest of Maharashtra, the effect of attending a meeting/training was only $6 \%$ but statistically significant at the $5 \%$ level. In Chennai, the $2 \%$ difference in consistent condom use was not statistically significant.

Consistent condom use was $8 \%$ higher among members of self-help group in Chennai than among matched non-members, but this effect was not statistically significant. However, for Mumbai, the difference was $10 \%(p=0.001)$.

\section{DISCUSSION}

We observed differential effect of intervention activities on individual and collective outcomes across districts in Tamil Nadu and Maharashtra, 18 months after the initiation of Avahan. This is not surprising as Avahan started implementing programmes across widely varying contexts. Standardising implementation is unlikely to lead to equal outcomes, especially with mobilisation of sex workers as interventions are deeply shaped by local prevailing political and social context. ${ }^{191315}$ Early in the India epidemic, the importance of context was exemplified by contrasting ideologies in Mumbai and Kolkata. The feminist ideology of protection against violence focused on welfare of sex workers in Mumbai with levels of collectivisation remaining insignificant. ${ }^{26}$ The Marxist ideology influencing Kolkata's women's organisations on the other hand saw sex work as legitimate labour empowering FSWs to act collectively. ${ }^{5} 27$ 
Table 3 Consistent condom use by level of active participation in interventions and membership of sex worker collectives in Tamil Nadu and Maharashtra

\begin{tabular}{|c|c|c|c|c|c|c|c|c|}
\hline & \multicolumn{8}{|c|}{ Consistent condom use with all clients } \\
\hline & Chennai, \% (n/N) & p Value & $\begin{array}{l}\text { Rest of } \\
\text { Tamil Nadu, } \\
\%(\mathrm{n} / \mathrm{N})\end{array}$ & p Value & Mumbai, \% (n/N) & p Value & $\begin{array}{l}\text { Rest of } \\
\text { Maharashtra, } \\
\%(\mathrm{n} / \mathrm{N})\end{array}$ & p Value \\
\hline Did not take part in a meeting/training & $80.1(223 / 279)$ & 0.067 & $37.5(219 / 588)$ & $<0.001$ & $67.7(833 / 1240)$ & 0.149 & $81.0(465 / 578)$ & 0.008 \\
\hline Took part in a meeting/training & $88.1(109 / 131)$ & & $58.0(608 / 1034)$ & & $72.8(257 / 356)$ & & $88.2(307 / 351)$ & \\
\hline Does not belong to a self-help group & $82.2(302 / 374)$ & 0.639 & $45.7(532 / 1140)$ & $<0.001$ & $67.2(950 / 1429)$ & $<0.001$ & $84.3(760 / 871)$ & 0.090 \\
\hline Belongs to a self-help group & $85.7(30 / 36)$ & & $62.3(295 / 482)$ & & $83.8(140 / 167)$ & & $75.8(43 / 58)$ & \\
\hline Does not belong to a sex work collective & $80.9(332 / 410)$ & - & $50.1(738 / 1450)$ & 0.361 & $70.1(1058 / 1539)$ & 0.013 & $83.7(757 / 911)$ & 0.960 \\
\hline Belongs to a sex work collective & $-(0 / 0)$ & & $55.2(89 / 172)$ & & $42.7(32 / 57)$ & & $83.3(15 / 18)$ & \\
\hline
\end{tabular}

It is thus important to take account of the differences in context, including prior programme effort, base levels of HIV and risk reduction practices and any predisposition to collectivise. As the first HIV cases in India were discovered in Chennai, prevention efforts started earlier. The state response in Tamil Nadu has historically been pro-active and coordinated with successive chief ministers actively supporting HIV control in addition to local NGOs demonstrating strong leadership. ${ }^{28} 29$ Large-scale USAID funding for sex workers interventions started in 1992 compared with 1999 for Maharashtra. When Avahan started in 2004, HIV prevalence among FSW was $42 \%$ in Maharashtra and 4\% in Tamil Nadu. ${ }^{29}$

Where intervention coverage had been lowest before Avahan started, in the districts of Tamil Nadu (excluding Chennai), we show the most impressive impact on consistent condom use. Consistent condom use was $21 \%$ higher among FSWs who attended meetings or trainings (59\% use) than among matched controls who had not attended ( $38 \%$ use). No impact was observed in Chennai, where condom use levels were highest before Avahan as implied by the $82 \%$ use among FSW not currently exposed in 2006. In Maharashtra outside of Mumbai, levels of consistent condom use were equally high among those not exposed (81\%), yet attending meetings or trainings did still have a significant effect on condom use (ATT $=6.2 \%$ ).
Sex workers' perception of collective efficacy and community support did vary by context, reflecting different degrees of vulnerability and structural barriers to community mobilisation. Overall, levels of perceived collective efficacy were low at the time of the survey in 2006 ranging from 20\% in Mumbai to $46 \%$ in the rest of Maharashtra with little difference between Chennai (26\%) and the rest of Tamil Nadu (28\%). In Mumbai where levels were lowest, members of self-help groups were significantly more likely to perceive that sex workers will stick together (ATT=31\%). In all other settings, women who attended trainings had higher collective efficacy than their matched controls.

Perceiving support from community members was again lowest among FSW in Mumbai $33 \%$ vs $65 \%$ in the rest of Maharashtra and much higher levels in Tamil Nadu). Neither attending meetings nor self-help groups showed an effect on community support yet $80 \%$ of the small minority of FSW belonging to sex workers collectives in Mumbai (4\%) did perceive higher community support. The low levels of perceived support in Mumbai confirm the city as a more challenging environment to implement community mobilisation. Mumbai typically attracts FSWs from all states, whereas in Chennai, FSW are a less heterogeneous group. In Chennai, FSWs perceived great support from their community (93\%), while previous

Table 4 Average treatment effect on the treated (ATT) - collective efficacy and community support

\begin{tabular}{|c|c|c|c|c|c|c|}
\hline & $\begin{array}{l}\text { Positive perception of } \\
\text { collective efficacy (treated) }\end{array}$ & $\begin{array}{l}\text { Positive perception of collective } \\
\text { efficacy (matched control) }\end{array}$ & ATT & $\begin{array}{l}\text { Bootstrap } \\
\text { SE }\end{array}$ & p Value & Observed \\
\hline \multicolumn{7}{|l|}{ Attending training/meeting } \\
\hline Rest of Maharashtra & 53.4 & 42.2 & 11.2 & 4.2 & 0.008 & 929 \\
\hline Rest of Tamil Nadu & 34.4 & 17.1 & 17.3 & 2.0 & $<0.001$ & 1622 \\
\hline Chennai & 44.9 & 15.0 & 29.9 & 5.4 & $<0.001$ & 410 \\
\hline \multicolumn{7}{|c|}{ Member of self-help group } \\
\hline Mumbai & 48.8 & 17.3 & 31.4 & 3.8 & $<0.001$ & 1596 \\
\hline \multicolumn{7}{|c|}{ Member of sex worker collective } \\
\hline Mumbai & 50.9 & 21.5 & 29.4 & 5.6 & $<0.001$ & 1576 \\
\hline \multirow[t]{2}{*}{ Rest of Tamil Nadu } & 43.3 & 19.1 & 24.1 & 4.4 & $<0.001$ & 1222 \\
\hline & $\begin{array}{l}\text { Positive perception of } \\
\text { community support (treated) }\end{array}$ & $\begin{array}{l}\text { Positive perception of community } \\
\text { support (matched control) }\end{array}$ & ATT & $\begin{array}{l}\text { Bootstrap } \\
\text { SE }\end{array}$ & p Value & Observed \\
\hline \multicolumn{7}{|l|}{ Attending training/meeting } \\
\hline Rest of Maharashtra & 73.8 & 62.0 & 11.8 & 4.1 & 0.004 & 929 \\
\hline Rest of Tamil Nadu & 81.5 & 66.0 & 15.5 & 2.7 & $<0.001$ & 1622 \\
\hline Chennai & 98.4 & 90.6 & 7.8 & 2.4 & 0.001 & 410 \\
\hline \multicolumn{7}{|c|}{ Member of self-help group } \\
\hline Rest of Maharashtra & 49.0 & 53.0 & -3.9 & 6.1 & 0.529 & 929 \\
\hline \multicolumn{7}{|c|}{ Member of sex worker collective } \\
\hline Mumbai & 80.0 & 35.4 & 44.5 & 4.7 & $<0.001$ & 1576 \\
\hline Rest of Tamil Nadu & 84.2 & 65.6 & 18.6 & 3.8 & $<0.001$ & 1222 \\
\hline
\end{tabular}


Table 5 Average treatment effect on the treated (ATT) - consistent condom use with all clients

\begin{tabular}{lllrlrr}
\hline & $\begin{array}{l}\text { Consistent } \\
\text { condom use } \\
\text { (\% among treated) }\end{array}$ & $\begin{array}{l}\text { Consistent } \\
\text { condom use } \\
\text { (\% among control) }\end{array}$ & ATT & $\begin{array}{l}\text { Bootstrap } \\
\text { SE }\end{array}$ & p Value & Observed \\
\hline Attending training & & & & & & \\
$\quad$ Rest of Tamil Nadu & 58.8 & 38.0 & 20.7 & 2.0 & $<0.001$ & 1622 \\
$\quad$ Chennai & 83.4 & 81.8 & 2.0 & 9.0 & 0.701 & 410 \\
$\quad \begin{array}{l}\text { Rest of Maharashtra } \\
\text { Member of self-help }\end{array}$ & 87.3 & 81.1 & 6.2 & 2.7 & 0.024 & 929 \\
$\quad$ Chennai & 84.8 & & & & & \\
$\quad$ Mumbai & 85.1 & 77.1 & 7.6 & 7.0 & 0.237 & 410 \\
\hline
\end{tabular}

collectivisation efforts were reported to be hampered by the highly stigmatised nature of sex work leading to fear of public disclosure of sex workers identity. ${ }^{12}$ Indeed, no sex worker reported to be a member of sex worker collective (grass roots organisations separate from the typical NGOs funded through Avahan). Thus, the longer history of prevention efforts in Chennai may have led to FSWs perceiving their peers as supportive, and this may have facilitated women gaining a sense of collective efficacy by participating in meetings and trainings (ATT $=30 \%$ ). A shared identity as a marginalised and stigmatised community helps members unite for the cause of collective benefit in times of crises. ${ }^{13} 30$ In the rest of Tamil Nadu, sex worker collectives were most prevalent and the concept of selfhelp groups has been long established for empowerment among the poor especially in rural areas, making it more easily transferable to the sex workers interventions. Overall, this represents a conducive environment for mobilising sex workers.

Lower perceived vulnerability-as measured by indicators of how FSW perceive collective agency and support in her community-was significantly associated with higher consistent condom use in districts outside of Mumbai and Chennai only. No doubt different structural factors are at play to shape vulnerability (beyond perceptions of collective power and support) and risk in large metropolises than in other settings. Unfortunately, we lack the qualitative contextual data needed to understand the complex relationship in different settings. The perception of a more supportive peer group in itself does not necessarily lead to risk reduction at the individual level. In our data, membership of a sex worker collective had a strong impact on both collective efficacy and on community support but was not associated with higher condom use. This may be because, although sex worker collectives have been able to grow because of HIV funding, their main priority is rights-based strategic change, with health outcomes secondary. ${ }^{8}$

At these early stages of Avahan scale-up, attending trainings and meetings showed overall biggest effects on condom use. Only in Mumbai did membership of a self-help group show higher consistent condom use (ATT $=10 \%$ ), though only $11 \%$ of sex workers had joined a self-help group at the time of the survey. The absence of significant effect of self-help groups elsewhere might be because these groups may not have been running for very long at the time of IBBA-I $(6.5 \%$ membership in the rest of Maharashtra and $8.5 \%$ in Chennai) resulting in low statistical power to show an effect. Also intervention strategies are cumulative with virtually all members of SHGs having attended training $(97 \%-$ $100 \%)$. In cases where a large proportion of FSW attending meetings had gone on to become members of a self-help group (eg, in Tamil Nadu districts outside of Chennai this was 46\%), we need to be cautious interpreting the effect of trainings on condom use (ATT $=21 \%$ ) since part of this effect might be attributable to membership of a self-help group. This is a common issue when interventions consist of multiple overlapping strategies as components cannot be evaluated separately.

Our study design and measures present some more limitation that imply caution for interpretation. Since promotion of consistent condom use is central to the programme, a higher reporting bias among sex workers most actively involved in the intervention cannot be ruled out. We believe to have reduced this bias by using the most conservative measure of consistent use by cumulating answers to all questions on condom use (with different types of clients), which were asked in different sections of the questionnaire. This exposed high levels of 'inconsistent' answers among those who had first asserted to 'always' use condoms (not shown).

Second, the use of single hypothetical questions to measure collective efficacy and community support do not fully capture the complex constructs we attempt to evaluate and their predictive validity is unknown. ${ }^{15}$ However, levels were significantly higher among members of the grass root level sex worker collectives whom we expect to perceive their peer group as supportive and having more collective efficacy.

Given the cross-sectional design, the direction of effect for associations between intervention strategies and sex workers perceptions can be debated. Women who perceive that sex workers will collectivise or support each other may be more likely to attend trainings and join self-help groups organised by NGOs. Her participation will in turn increase her involvement and her perception of collective action and support. For example, members of sex workers collectives who we may safely assume had higher collective efficacy before the scale-up of Avahan were more likely to attend meetings: in the rest of Tamil Nadu, 97\% of members of SWC versus $51 \%$ of non-members attended the trainings/meetings. Community mobilisation is not a linear or one-off step, but a complex one more easily implemented in certain contexts than others with standardised intervention methods not giving equal results. It warns us against interpreting the effect size (ATT) as simply intervention impact on vulnerability indicators. This reservation does not apply to the impact of intervention on higher condom use as reverse causality is rather unlikely.

Like with other non-randomised studies, it is not possible to control for unmeasured confounders. In our application of PSM, we failed to find balanced p-score models for the exposure to self-help groups in the rest of Tamil Nadu and for exposure to training in Mumbai because the difference between the exposed and non-exposed sex workers could not be fully explained by the observed covariates. Unfortunately, in-depth information on how communities have mobilised is not available for the clusters where FSW were sampled. We therefore cannot fully 'explain' all of the differential as we lack knowledge about the specifics of local variability. ${ }^{31}$ This is especially pertinent for Mumbai, where high levels of HIV go hand-in-hand in with high 


\section{What is already known on this subject}

- Peer-led interventions and community mobilisation have been successful in risk reduction among FSWs, but evidence from case studies shows they are not necessarily transferable.

- Little is known about levels of peer and community support in different settings and how they affect or can be influenced by community mobilisation activities rolled out in the context of large-scale FSW interventions.

\section{What this study adds}

- Large scale-up of FSW interventions can achieve considerable impact on levels of consistent condom use, especially where levels were low.

- The effect of interventions needs to be evaluated in their historical and local context. High perceived levels of community support occur even where stigma has acted as barriers to collectivisation. In the most complex settings where FSWs are a heterogeneous group, vulnerability remains highest.

- Involving FSW in community mobilisation is not a linear process, and participation in interventions is influenced by, and in turn influences, perception of solidarity and support.

vulnerability and risk behaviour. Nevertheless, in illustrating different intervention effect according to different levels of vulnerability, we re-affirm the importance of considering context when transferring mobilisation efforts to other settings.

\section{CONCLUSIONS}

It is important to evaluate the effect of HIV prevention among FSW in their historical and local context. Effect of interventions on risk reduction is largest where greater gains were possible because of low condom use at the start. The strategies to build stronger peer relationships among FSWs seem promising as the perception of solidarity and support was significantly higher among those participating in interventions, even in more complex contexts such as Mumbai.

Contributors MG reviewed the literature and contributed to all drafts; $A B$ did the statistical analyses with input from TB and SSS in writing the methods; MC conceptualised and wrote the main parts of the paper with input from SB; all other authors contributed to several drafts of the paper.

Funding Bill and Melinda Gates Foundation grant no. OPP1006842. Providing salary money for evaluation.

\section{Competing interests None}

Ethics approval Ethics approval was provided by the National AIDS Research Institute (ICMR) and the National Institute of Epidemiology (ICMR).

Provenance and peer review Commissioned; externally peer reviewed.

\section{REFERENCES}

1. Evans C, Lambert $\mathrm{H}$. Implementing community interventions for HIV prevention: Insights from project ethnography. Soc Sci Med 2008;66:467-78.

2. Shahmanesh M, Patel V, Mabey D, et al. Effectiveness of interventions for the prevention of HIV and other sexually transmitted infections in female sex workers in resource poor setting: a systematic review. Trop Med Int Health 2008;13:659-79.

3. Basu I, Jana S, Rotheram-Borus MJ, et al. HIV prevention among sex workers in India. J Acquir Immune Defic Syndr 2004:36:845-52.

4. Jana S, Basu I, Rotheram-Borus MJ, et al. The Sonagachi Project: a sustainable community intervention program. AIDS Educ Prev 2004;16:405-14.

5. Ghose T, Swendeman D, George S, et al. Mobilizing collective identity to reduce HIV risk among sex workers in Sonagachi, India: the boundaries, consciousness, negotiation framework. Soc Sci Med 2008:67:311-20.

6. Swendeman D, Basu I, Das S, et al. Empowering sex workers in India to reduce vulnerability to HIV and sexually transmitted diseases. Soc Sci Med 2009;69:1157-66.

7. Blankenship KM, Friedman SR, Dworkin S, et al. Structural interventions: concepts, challenges and opportunities for research. J Urban Health 2006;83:59-72.

8. Cornish F. Targeting HIV or targeting social change? The role of Indian sex worke collectives in challenging gender relations. In: Boesten J, Poku N, eds. Gender and HIVIAIDS: Critical Perspectives from the Developing World. London: Ashgate Publishing Ltd, 2009:121-42.

9. Cornish F, Campbell C. The social Conditions for successful peer education: a comparison of two HIV prevention programs run by sex workers in India and south Africa. Am J Community Psychol 2009;44:123-35.

10. Campbell C, Cornish F. Towards a "fourth generation" of approaches to HIV/AIDS management: creating contexts for effective community mobilisation. AIDS Care 2010;22(Suppl 2):1569-79.

11. Gurnani V, Beattie TS, Bhattacharjee P, et al; CFAR Team. An integrated structural intervention to reduce vulnerability to HIV and sexually transmitted infections among female sex workers in Karnataka state, south India. BMC Public Health 2011:11:755.

12. Asthana S, Oostvogels R. Community participation in HIV prevention: problems and prospects for community-based strategies among female sex workers in Madras. Soc Sci Med 1996;43:133-48.

13. Cornish F, Ghosh R. The necessary contradictions of 'community-led' health promotion: a case study of HIV prevention in an Indian red light district. Soc Sci Med 2007:64:496-507.

14. Halli SS, Ramesh BM, O'Neil J, et al. The role of collectives in STI and HIV/AIDS prevention among female sex workers in Karnataka, India. AIDS Care 2006;18:739-49.

15. Blankenship KM, West BS, Kershaw TS, et al. Power, community mobilization, and condom use practices among female sex workers in Andhra Pradesh, India. AIDS 2008;22(Suppl 5):S109-16.

16. Biradavolu MR, Burris S, George A, et al. Can sex workers regulate police? Learning from an HIV prevention project for sex workers in southern India. Soc Sci Med 2009;68:1541-7

17. Saidel T, Adhikary R, Mainkar M, et al. Baseline integrated behavioural and biological assessment among most at-risk populations in six high-prevalence states of India: design and implementation challenges. AIDS 2008;22(Suppl 5):S17-34.

18. Rosenbaum PR, Rubin DB. The central role of the propensity score in observationa studies for causal effects. Biometrika 1983;70:41-55.

19. Caliendo M, Kopening R. Some Practical Guidance for the Implementation of Propensity Score Matching. Discussion Paper No. 1588. Bonn: IZA, 2005.

20. Lechner M. Some practical issues in the evaluation of heterogeneous labour marke programmes by matching methods. J $R$ Stat Soc 2002;165:59-82.

21. Oakes M, Kaufman JS. Methods in Social Epidemiology. San Francisco, California: John Wiley \& Sons, 2006.

22. Dehejia R. Practical propensity score matching: a reply to Smith and Todd. J Econom 2005;125:135-364.

23. Smith J, Todd P. Reconciling conflicting evidence on the performance of propensity score matching methods. Am Econ Rev 2001;91:112-18.

24. Yanovitzky I, Zanutto E, Hornik R. Estimating casual effects of public health education campaigns using propensity score methodology. Eval Program Plann 2005:28:209-20.

25. D'Agostino RB. Tutorial in Biostatistics: propensitu score methods for bias reduction in the comparison of a treatment to a non-randomized control group. Stat Med 1998:17:2265-81.

26. Shah S. Sex work in the global economy. New Labor Forum 2003;12:74-81

27. Ray R. Women's movements and political fields: a comparison of two Indian cities. Social Problems 1998;45:21-36. http://www.jstor.org/stable/3097141

28. Ramasundaram S. Can India avoid being devastated by HIV? Yes, by scaling up local prevention efforts targeted at the most vulnerable groups. BMJ 2002;324:182-3

29. Kumar R, Mehendale SM, Panda S, et al. Impact of targeted interventions on heterosexual transmission of HIV in India. BMC Public Health 2011:11:549.

30. Campbell C, MacPhail C. Peer education, gender and the development of critical consciousness: participatory HIV prevention by South African youth. Soc Sci Med 2002; $55: 331-45$

31. Lambert H. Commentary: categorizing risks for HIV among female sex workers: the importance of context. Int J Epidemiol 2010;39:448-9. 